\title{
Claire Le Ninan, Le Sage Roi et la Clergesse. L'Écriture du politique chez Christine de Pizan
}

\section{Stefania Vignali}

\section{(2) OpenEdition}

1 Journals

Édition électronique

URL : http://journals.openedition.org/studifrancesi/2091

DOI : 10.4000/studifrancesi.2091

ISSN : 2427-5856

Éditeur

Rosenberg \& Sellier

\section{Édition imprimée}

Date de publication : 1 avril 2014

Pagination : 123-124

ISSN : 0039-2944

\section{Référence électronique}

Stefania Vignali, «Claire Le Ninan, Le Sage Roi et la Clergesse. L'Écriture du politique chez Christine de Pizan », Studi Francesi [En ligne], 172 (LVIII | I) | 2014, mis en ligne le 01 avril 2014, consulté le 18 septembre 2020. URL : http://journals.openedition.org/studifrancesi/2091 ; DOI : https://doi.org/ 10.4000/studifrancesi.2091

Ce document a été généré automatiquement le 18 septembre 2020

\section{(c) (i) $\odot$}

Studi Francesi è distribuita con Licenza Creative Commons Attribuzione - Non commerciale - Non opere derivate 4.0 Internazionale. 


\title{
Claire Le Ninan, Le Sage Roi et la Clergesse. L'Écriture du politique chez Christine de Pizan
}

\author{
Stefania Vignali
}

\section{RÉFÉRENCE}

CLAIRE LE NINAN, Le Sage Roi et la Clergesse. L'Écriture du politique chez Christine de Pizan, Paris, Honoré Champion, 2013, pp. 434.

1 Ce volume, qui constitue le remaniement d'une thèse soutenue en 2004, renferme une intéressante étude sur l'écriture du politique dans l'œuvre de Christine de Pizan. La brève introduction qui ouvre cet essai s'articule en quatre paragraphes, consacrés respectivement à l'illustration du contexte historique particulièrement favorable à la composition de traités politiques, à la définition du politique chez Christine de Pizan et à son idéal du prince sage, à l'établissement du corpus de travail - qui, sans délaisser la production lyrique de l'auteure, se concentre plus particulièrement sur les œuvres en prose à caractère didactique - et enfin aux différentes représentations de l'écrivain dans ses textes.

2 Le volume se structure en deux grandes parties. Dans la première (Représentation de l'écrivaine en clergesse: présence du 'moi' et construction de l'autorité), C.L.N. analyse les différentes postures assumées par Christine de Pizan dans la construction d'une image idéale du 'moi', qui soit digne de recevoir la confiance des puissants auxquels elle s'adresse. Une première étape, essentielle, est représentée par la création d'une identité cléricale, qui paradoxalement ne peut se faire qu'à travers l'acquisition d'une autorité dérivée de son statut de veuve. L'analyse se poursuit avec la description des différentes fonctions cléricales que Christine s'attribue, et tout d'abord celle d'historienne; l'A. analyse l'emploi savant qu'elle fait de la matière historique, et qui s'entrelace avec son expérience personnelle afin de mettre en valeur sa visée 
didactique, ainsi que son désir de faire reconnaître ses qualités intellectuelles. Ensuite, l'attention se concentre sur le rôle de précepteur que Christine entend jouer; la relation pédagogique qu'elle veut instaurer avec le jeune héritier Louis de Guyenne passe, selon C.L.N., à travers l'utilisation de divers procédés rhétoriques comme le tutoiement, l'autocitation, la compilation ou le recours à l'exemplum, ces deux derniers tendant plus particulièrement à illustrer les connaissances que l'écrivaine, en philosophe, souhaite dispenser à son élève. Le dernier aspect analysé est la posture de prophète, degré ultime de sagesse, que Christine assume dans son dernier ouvrage et à travers lequel elle met en évidence son savoir exceptionnel, ainsi que sa capacité d'interpréter les signes divins.

3 La deuxième partie ( $L$ a clergesse et son texte: rhétorique et leçon politique) se concentre sur l'étude du style prosaïque adopté par Christine dans ses œuvres didactiques. C.L.N. montre que les procédés rhétoriques mis en œuvre pour convaincre le lectorat princier s'inscrivent amplement dans la tradition de la littérature politique du temps. L'analyse des techniques de réécriture employées dans le cadre du procédé de la compilation (changements lexicaux, amplification et réduction), met en évidence les capacités qu'a Christine de créer une unité textuelle. L'A. passe ensuite à examiner l'usage des personnifications dans l'œuvre christinienne et elle insiste en particulier sur le personnage de Libera qui figure dans l'Advision Cristine; en effet, c'est le discours de la Dame Couronnée qui permet l'élaboration de l'allégorie de la France. À travers la métaphore maternelle, la métaphore agricole et la métaphore des animaux, appartenant aux topoï de la littérature politique de la fin du Moyen Âge, Christine permet aussi aux princes de se confronter à leurs vices et à la réalité déplorable dans laquelle le royaume est plongé. Le dernier chapitre du volume se concentre sur une étude analytique du Livre des bonnes mœurs du sage roi Charles $V$, considéré le texte fondateur de toute l'œuvre politique postérieure de Christine; C.L.N. analyse les procédés à travers lesquels l'écrivaine crée l'image du prince idéal: l'accumulation d' exempla, toujours choisis en fonction du destinataire de l'œuvre, permet l'identification du lecteur avec l'«acteur», tandis que le jeu d'analogies et de relations constitue une première étape vers la modélisation de la figure royale: Charles $\mathrm{V}$ est représenté comme un exemple à imiter, le roi sage par excellence, image qui sera reprise par Christine dans ses œuvres postérieures.

4 La Bibliographie divisée en sections thématiques, un Index des noms et des Titres, ainsi qu'un Index des Notions et la Table des matières complètent ce volume. 